\title{
Dicarboxylic aminoaciduria
}

INSERM

\section{Source}

INSERM. (1999). Orphanet: an online rare disease and orphan drug data base.

Dicarboxylic aminoaciduria. ORPHA:2195

Dicarboxylicaminoaciduria is characterised by infantile-onset hypoglycaemia and hyperprolinaemia associated, in certain cases, with intellectual deficit. 